\title{
nombalina
}

(8)

\section{O mundo natural e o espaço do humano na poesia trágica de Séneca: Troades e Thyestes}

\author{
Autor(es): $\quad$ Matias, Mariana Horta e Costa \\ Publicado por: Associação Portuguesa de Estudos Clássicos; Imprensa da \\ URL \\ persistente: URI:http://hdl.handle.net/10316.2/31775 \\ DOI: $\quad$ DOI:http://dx.doi.org/10.14195/978-989-721-069-3_21 \\ Accessed : $\quad$ 26-Apr-2023 15:09:56
}

A navegação consulta e descarregamento dos títulos inseridos nas Bibliotecas Digitais UC Digitalis, UC Pombalina e UC Impactum, pressupõem a aceitação plena e sem reservas dos Termos e Condições de Uso destas Bibliotecas Digitais, disponíveis em https://digitalis.uc.pt/pt-pt/termos.

Conforme exposto nos referidos Termos e Condições de Uso, o descarregamento de títulos de acesso restrito requer uma licença válida de autorização devendo o utilizador aceder ao(s) documento(s) a partir de um endereço de IP da instituição detentora da supramencionada licença.

Ao utilizador é apenas permitido o descarregamento para uso pessoal, pelo que o emprego do(s) título(s) descarregado(s) para outro fim, designadamente comercial, carece de autorização do respetivo autor ou editor da obra.

Na medida em que todas as obras da UC Digitalis se encontram protegidas pelo Código do Direito de Autor e Direitos Conexos e demais legislação aplicável, toda a cópia, parcial ou total, deste documento, nos casos em que é legalmente admitida, deverá conter ou fazer-se acompanhar por este aviso.

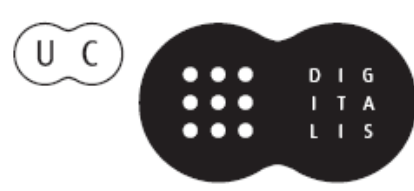




\section{Espaços e Paisagens}

\section{Antiguidade Clássica e Heranças Contemporâneas}

Vol. I Línguas e Literaturas. Grécia e Roma

Francisco de Oliveira, Cláudia Teixeira, Paula Barata Dias (coords.)

IMPRENSA DA UNIVERSIDADE DE COIMBRA 


\title{
O MUNDO NATURAL E O ESPACO DO HUMANO NA POESIA TRÁGICA DÉ SÉNECA: TROADES E THYESTES
}

\author{
Mariana Horta e Costa Matias \\ Universidade de Coimbra \\ CECH/FCT \\ marianamatias@sapo.pt
}

\begin{abstract}
Sequi naturam - living according to Nature - was to the Stoic doctrine followers' one of the most vital aphorisms and, in fact, the supreme and highest virtue to accomplish, an ideal that Seneca, poet and thinker, never ceased to reiterate in his philosophical works. That same notion of "naturalism" - in its most diverse semantic shades - manifests itself in Seneca's corpus tragicum, namely in two of the plays concerning the mythological nucleus of Atreus' house: Troades and Thyestes.

In his tragedies the dramatist from Corduba embraces nature not as a mere Stoic inert notion, but as an aesthetic and dramatic principle of extraordinary significance. Natura shines as a privileged poetic technique of expression of emotions and accurate and distinctive drawing of natural spaces.
\end{abstract}

Keywords: cosmic sympatheia, humanity, humanization, natura/nature, Roman tragedy, Seneca, Stoic philosophy.

Palavra-chave: humanidade, humanização, natura/natureza, Seneca, tragédia romana.

Finaliza Bocage o soneto intitulado "Descrevendo uma noite tempestuosa" com os seguintes versos: "Quer no horror igualar-me a Natureza:/ Porém cansa-se em vão, que no meu peito/ há mais escuridade, há mais tristeza». ${ }^{1}$ Julgamos, em certa medida, encontrar nestas breves palavras do pré-romântico português algum do sentimento poético-filosófico que Séneca tão bem soube transpor para a sua negra tragediografia: a inquebrável relação entre Homem e Natureza.

O filósofo Ernst Cassirer afirma que o estóico, à semelhança do homem primitivo, comunga de uma visão da natureza que é, na sua essência, simpática, na medida em que o ser humano vivencia um profundo sentimento de harmonia com o mundo natural. ${ }^{2}$ Esta convicção de que existe um laço comum que une todas as coisas, nomeadamente o homem e a natureza, e que aquele é uma parte desse todo, relaciona-se também, de forma directa, com

\footnotetext{
${ }^{1}$ Bocage 2005: 65.

${ }^{2}$ Cf. E. Cassirer 1995: 78.
} 
as noções de macro e microcosmos. A organização do Universo - entendido como macrocosmos - serve de modelo ${ }^{3}$ ao ser humano - o microcosmos -, numa visão posteriormente reaproveitada pelo Humanismo, e radicada no contexto da cultura renascentista.

Assim, foi apoiado em ideais filosóficos como a concepção da natura na sua intrínseca relação com Razão e Providência, e as noções de sympatheia ton olon e de macro e microcosmos, que Séneca, o poeta-filósofo, abraçou os "ensinamentos" da doutrina do Pórtico e "moldou" uma natureza que, nas suas tragédias, se revela mais do que um mero conceito de filosofia em actuação passiva, e que se assume como um factor verdadeiramente estético, de inigualável expressividade retórica e poético-dramática. Charles Segal considera mesmo a existência de duas formas distintas, mas complementares, da afirmação dramática do herói senequiano, que se consubstanciam no "I-statement", a auto-dramatização da magnitude emocional, do sofrimento; por outro lado, na estratégia dramática da projecção cósmica que significa, por sua vez, o envolvimento de todo o mundo na desgraça humana, na relação de base estóica da sympatheia. ${ }^{4}$

O Cordubense, exímio na construção de quadros vivos, herança de um pictorismo de que Pacúvio foi precursor, privilegia a descrição de ambientes naturais, e modela a natureza para que esta deixe de funcionar como simples cenografia sobre a qual se vão desenrolando os acontecimentos. $O$ que Séneca faz é conferir personalidade própria à Natureza universal e racional de que tanto fala nos seus escritos filosóficos, corporalizando-a na influência directa que esta exerce no comportamento das personagens; por outro lado, a natureza (physis) humana e particular das figuras por si criadas também ela influi sobre os elementos físicos que a circundam, numa verdadeira ligação de interdependência. Muitas das vezes, senão quase sempre, a paisagem natural (exterior) é o reflexo metafórico de uma paisagem interior, o espelho racional dos estados de alma das personagens intervenientes.

Troades, verdadeira liturgia fúnebre, "tragédia de luto" nas palavras de Florence Dupont $t^{5}$, abre com Tróia em ambiente de destruição e de morte. $\mathrm{O}$ fogo, o fumo e as cinzas (vv. 15-21) são protagonistas e estabelecem a imagem de uma cidade arrasada, de uma pátria vencida, mas também o espelho da alma de um povo e, em especial, de Hécuba, despojada, que sofre sem esperança de ressurreição.

A natureza envolvente partilha da dor do povo troiano e assistimos a uma verdadeira sympatheia entre as duas realidades. A escuridão, o clima de terror e o desolamento que enformam este ambiente exterior, carregado de simbolismos e presságios, são o reflexo de uma paisagem interior conturbada - a do espírito de Hécuba. Falamos de uma figura que se identifica, logo desde o início da peça, com a própria cidade, numa espécie de simbiose emocional, de relação de interdependência, como se as duas fossem uma e a mesma entidade: me uideat et te, Troia (v. 4).

${ }^{3}$ Cf. J. A.Segurado e Campos 1997: 80.

${ }^{4}$ C. P. Segal 1983:173.

${ }^{5}$ F. Dupont 1985: 206. 
Ainda no mesmo drama, encontramos a rhesis de Taltíbio, a descrição pormenorizada do cataclismo que o espectro de Aquiles desencadeia com a sua anábase (vv. 170-202). Uma revolução que nos mostra, num primeiro momento, uma natureza revoltada que prepara a chegada do fantasma do herói grego, verdadeiro reflexo do ethos desta personagem, entidade infernal, vencedora também na morte. Em seguida, a natureza volta à sua ordem natural, qual fiel serva do espectro, e todos os seus elementos se mostram complacentes, agora que a ira de Aquiles foi aplacada, ao reclamar a morte de Políxena (vv.199-202).

Em Thyestes, atente-se no furor que invade todo o espírito de Atreu, nos versos 260-266. A tremenda agitação que toma conta do tirano leva a que a terra ruja desde as profundezas (imo mugit e fundo solum), o dia sereno troveje (tonat dies serenus), a casa ranja (ut fracta tectis crepuit) e os próprios Lares, atemorizados, desviem o olhar (et moti lares/ uertere uultum). Mais uma vez, a projecção da violência interior na paisagem natural.

Também o desenho pormenorizado do bosque secreto, onde tem lugar o assassínio dos filhos de Tiestes às mãos de Atreu (vv. 650-682), preenche os requisitos daquela que é a representação da natureza, por excelência, da tragediografia senequiana - o locus horrendus -, ao apresentar todos os elementos convencionais: a fonte de águas estagnadas; a escuridão; os fantasmas, entre outros. Séneca projecta nesta paisagem todo um mundo interior vivido por Atreu e pela família dos Pelópidas. numa profunda e completa identificação entre o furor, a insania de um genus criminoso e o seu habitat natural: a domus impia.

Destacamos outra "forma" de natureza: a exploração da paisagem geográfica do poder, designadamente através do uso da imagem arquitectural, como modo elaborado de pensar e concretizar esteticamente uma organização sociopolítica. Nesta medida, a mansão dos Pelópidas ocupa estrategicamente a parte mais elevada da cidade, numa estrutura, remota no tempo e inacessível no espaço, que domina e controla uma urbs aterrorizada (vv. 641-645):

\section{In arce summa Pelopiae pares est domus conuersa ad Austros, cuius extremum latus aequale monti crescit atque urbem premit et contumacem regibus populum suis habet sub ictu;}

Falamos, pois, de uma topografia que surge como representação deliberada de uma paisagem de controlo, espelho fiel da natureza terrível desta família.

Deste modo, a natureza senequiana não é uma natureza morta, nem muda. $\mathrm{Na}$ verdade, ela fala, à sua maneira, com a galeria de figuras senequianas. Assim, na esteira da concepção providencial e racional da natura estóica, os elementos naturais intervêm, sempre que podem, na acção, influindo o seu poder nas personagens que o Cordubense constrói para as suas míticas histórias. Em nada se mostra alheia à diversidade das atitudes humanas, ao revelar o seu 
acordo ou desagrado, ao manifestar o seu júbilo, a sua tristeza ou a sua revolta perante os passos tremidos que as personagens vão trilhando.

A sensibilidade, a humanização da natureza senequiana é bem patente, por exemplo, no relato do ritual sacrificial de Atreu (vv. 696-702): todo o bosque estremeceu (lucus tremescit); a sala tremeu (tota succusso solol nutauit aula); o vinho libado escorreu sobre o fogo, transformado em sangue (libata in ignes uina mutato fluunt/ crueenta Baccho); da fronte de Atreu tombou mais do que uma vez o diadema (regium capiti decus/ bis terque lapsum est); e o marfim do templo chorou o mal que era obrigado a testemunhar (fleuit in templis ebur). E quando o tirano se prepara para cozinhar os corpos dos sobrinhos, os elementos rebelam-se novamente: o fogo foge, mas é forçado a arder, e o próprio fumo se evola de forma estranha (vv. 767-775).

No fim do relato, surge a referência a uma das alterações naturais que domina toda a acção dramática de Thyestes, a fuga do sol aquando do crime de Atreu: O Phoebe patiens, fugeris retro licet/ medioque ruptum merseris caelo diem,/ sero occidisti (vv. 776-778) O motivo do eclipse solar, o leitmotiv do mundus inuersus, vivido pelas várias personagens em diferentes perspectivas, como se ocorresse uma e outra vez, enforma metaforicamente toda a peça e inscreve-se na imagética moral dos céus como reflexo da ordem ou desordem moral da vida humana, símbolo da completa inversão da harmonia cósmica. Séneca abraça esse motivo tradicional, conferindo-lhe uma dimensão bem mais alargada. ${ }^{6}$ Perante as atrocidades cometidas pelo ser humano, o cosmos vê-se obrigado a alterar o seu curso habitual, e a fuga do sol revela-se a sua reacção mais violenta.

No funesto banquete, ainda em Thyestes, é a natureza que tenta alertar o irmão de Atreu para o perigo que corre e o mal que comete, e é ele próprio, embriagado pelo álcool e inebriado pelo cheiro e sabor das paixões, que conta que lhe tombam da fronte as flores festivas, que o seu cabelo repentinamente se eriça com horror, que lhe caem lágrimas involuntariamente e que solta gemidos sem querer (vv. 947-951):

Vernae capiti fluxere rosae,
pingui madidus crinis amomo
inter subitos stetit horrores,
imber uultu nolente cadit,
uenit in medias uoces gemitus.

Tiestes, porém, teima em seguir o affectus, não dando ouvidos à ratio, materializada aqui pela natura.

No momento em que o pérfido Atreu oferece ao irmão o copo que contém o sangue dos sobrinhos a beber e este fraternalmente o aceita, também os elementos naturais se revoltam e manifestam a sua repulsa de forma vigorosa: dos lábios lhe foge o vinho; o fogo deixa de reluzir e a noite esconde-se, e as próprias mãos se negam a segurar a taça (vv. 985-995).

${ }^{6}$ Vide W. H. Owen 1968: 291-313. 
Note-se o interesse que a natureza humana, isto é, física desperta em Séneca, nomeadamente aquando do delineamento dos caracteres das figuras, num comprazimento tipicamente estóico na descrição da sensação, ou melhor, da expressão exterior dos sentimentos. Falamos da exploração da "fisicalidade" do ser humano, que o tragediógrafo eleva à sua expressão máxima numa relação de (quase) interdependência com o seu gosto acentuado pelo macabro e pela morbidez. É visível esse sentido de "corporalidade", por exemplo, no ritual de dolor desbragado das cativas troianas que, em Troades, em honra de Heitor, soltam os cabelos, os cobrem com cinza, desnudando o peito e lacerando-o com violentos golpes. Um lamento e um luto que se consumam numa automutilação em que o corpo surge como templo da dor (vv. 117-124); ou no relato pormenorizado das mortes dos jovens Astíanax e de Políxena, autênticos modelos de sapientia estóica (respectivamente, vv. 1110-1116; 1157-1164).

Quando, em Thyestes, o mensageiro relata o assassínio cruel dos filhos de Tiestes e a preparação dos corpos para o banquete da pretensa reconciliação entre os irmãos, a alargada descrição (vv. 683-738) revela bem o "goût de l'horrible" que o poeta-filósofo explora, não pelo mero gosto do macabro, mas porque o pictorismo da crueza contribui de forma impressionante para a caracterização apurada das personagens e dos ambientes.

Verificamos facilmente que uma das preocupações vitais do drama senequiano se centra no delineamento dos caracteres das figuras, e é nesse desenho burilado que o Cordubense revela a sua maior mestria. Concorre para o aprofundamento psicológico dos ethe o recurso a comparações, metáforas e símiles com elementos do mundo natural, animal e vegetal. A título de exemplo, em Troades, a grandeza da physis hereditária de Astíanax é ilustrada através da comparação com um tenro novilho que, desde cedo, comanda o gado, à semelhança do pai (vv. 537-540); ou, equiparada à cinza de um grande fogo que depressa recupera as suas forças e se ateia novamente (vv. 544-545).

Mireille Armisen-Marchetti constata que, apesar de o autor enriquecer a sua tragediografia com motivos tradicionais, a personalização desse legado passa por uma opção e selecção de imagens que não se define somente como estratégia estilística, mas é ela também um dos meios que Séneca elegeu para nos dar a conhecer algum do seu mundo psicológico, ético e estético. ${ }^{7}$ Nota-se, assim, especial predilecção - que se vem a revelar uma constante no imaginário senequiano - pelo movimento e pela metamorfose, influência porventura ovidiana.Um movimento que resulta, habitual e consequentemente,em violência, e numa exacerbação do pathos dramático ao servir-se de elementos "móveis" como o mar, o fogo, o vento, ou a natureza violenta dos animais selvagens, na expressão magnífica do furor, do descontrolo humano. ${ }^{8}$ Veja-se a comparação de Atreu, primeiro com um tigre, depois com um leão, na sua ferocidade sem limites aquando do assassínio dos três sobrinhos (respectivamente, vv. 707-713 ; 732-738), à semelhança de Ulisses, em Troades, quando se acerca de Astíanax

\footnotetext{
${ }^{7}$ M. Armisen-Marchetti 1989: 374.

${ }^{8}$ Ibid., 360.
} 
(vv. 796-799). A movimentação irracional das feras surge como metáfora dos comportamentos de cólera, furor e insania do ser humano.

Não podemos deixar de fazer alusão à vertente toponímica, à geografia trágica que Séneca abraça no seu drama e que não deve entender-se como gratuita estratégia retórica, pois esta alcança um valor verdadeiramente metafórico. Por exemplo, os perfumes de distância, exotismo e de violência que alguns topónimos emanam contribuem para o delineamento preciso dos caracteres - veja-se a comparação de Atreu com um tigre das florestas do Ganges, Índia (vv. 713-716), ou um leão da Arménia (vv. 732-738), em referências a paragens remotas, entendidas como locais de costumes selvagens e de barbárie. ${ }^{9} \mathrm{Ou}$, por exemplo, em Troades, o extenso catálogo de referências geográficas, locais para onde o coro de cativas conjectura ir parar (vv. 814- -850). Também aqui concordamos com Zélia de Almeida Cardoso, quando afirma que a geografia do desconhecido e do longínquo simboliza o estado de alma destas mulheres perdidas no espaço e no tempo. ${ }^{10}$ Como defende Gianpero Rosati, poder-se-á falar de uma espécie de "determinismo do espaço", na medida em que cada personagem parece estar vinculada aos locais, às paisagens que povoa e em que se move. As figuras senequianas são os lugares que habitam. ${ }^{11}$

Em jeito de conclusão, e aceitando a premissa de Rossana Mugellesi de que os dois elementos cardeais do drama senequiano são a participação da natureza e o aprofundamento psicológico do pathos emocional ${ }^{12}$, julgamos poder afirmar que a natureza trágica senequiana é ela uma verdadeira natura animata, paisagem que deixa de ser pura cenografia, elemento unicamente descritivo, para adquirir o estatuto de "paisagem trágico-dinâmica". Esta revela-se como uma personagem dramática real que se distingue, acima de tudo, pela sua humanização e humanidade. ${ }^{13}$

\section{Bibliografia}

F.-R. Chaumartin (1999), Sénèque, Tragédies. T. I-III. Paris.

M. Armisen-Marchetti (1989), Sapientiae Facies: étude sur les images de Sénèque. Paris.

M. M. B. Du Bocage (2005), Obras Escolhidas. I vol. Lisboa.

M. Grant (2000), "Seneca’s tragic geography", Latomus 59.1 88-95.

E. Cassirer (21995), Ensaio sobre o Homem. Carlos Branco (trad.), Lisboa.

R. Mugellesi (1973), "Il senso della natura in Seneca tragico" in Argentea aetas in memoriam E. V. Marmorale. Génova, 29-66.

W. H. Owen (1968), "Commonplace and Dramatic Symbol in Seneca's

\footnotetext{
${ }^{9}$ Vide M. Grant 2000: 88-95.

${ }^{10}$ Z. A. Cardoso 1997: 21.

${ }^{11}$ G. Rosati 2002: 229.

${ }^{12}$ R. Mugellesi 1973: 65-66.

${ }^{13}$ Vide R. Mugellesi 1973: 56.
} 
Tragedies", TAPhA 99 291-313.

G. Rosati (2002), "La scena del potere. Retorica del paesaggio nel teatro di Seneca" in Hispania terribus omnibus felicior: Premesse ed esiti di un processo di integrazione. Pisa 225-239.

C. P. Segal (1983), "Boundary Violation and the Landscape of the Self in Senecan Tragedy", $A \mathcal{E} \odot A 29$ 172-87.

J. A. Segurado e Campos (1997), "Ratio e Voluntas no Pensamento de Séneca", Classica 22 79-92. 